\title{
AC 2007-1117: EFFECTIVE PEDAGOGICAL TECHNIQUES IN OPERATIONS RESEARCH COURSES INTENT ON IMPROVING ANALYSIS SKILLS AND REPORT-WRITING
}

Sima Parisay, California State Polytechnic University-Pomona 


\title{
Effective Pedagogical Techniques in Operations Research Courses Intent on Improving Analysis Skills and Writing Report
}

\author{
Dr. Sima Parisay \\ California State Polytechnic University, Pomona
}

\begin{abstract}
Powerful Operations Research (OR) softwares provide many of the analytical features needed to solve OR problems. However, students lack the skills required for problem formulation, efficient application of software features, and communication of their findings in a report format. An effective pedagogy is developed to assist students with problem formulation while enforcing analytical skills and guiding writing reports. I have utilized pedagogy tools such as handouts with specific guidelines and extensive examples, in-class discussions, homework assignments, and a final project to enforce report writing and analytical thinking. Moreover, I stress the importance of analyzing the software's solutions further to obtain more useful information.
\end{abstract}

Though writing a "Report to a Manager" has been an element of my OR courses since 1999, the new approach has evolved in the last three years. This new approach is aimed at helping students to better understand, utilize, and communicate OR techniques. The pedagogy proved to be very effective, with an overwhelmingly positive feedback from students.

\section{1- Introduction}

Operations Research courses usually start with discussion of Linear Programming (LP): formulating a problem; using simplex method to arrive at the solution; explaining how to mathematically obtain shadow price and reduced cost, as well as allowable ranges; and discussing topics in sensitivity analysis. Later, a selection of other techniques, such as Transportation, Decision Theory, and Markov Chain, is usually covered.

We are a state university with the ten-week quarter system, emphasizing teaching. Our department offers two senior level undergraduate courses in the OR field: Operations Research I (IE 416) and Operations Research II (IE 417). The two OR courses are offered as web assisted courses and their websites are at the following URL: http://www.csupomona.edu/ sparisay/Courses/ie416 http://www.csupomona.edu/ sparisay/Courses/ie417

The textbook used for these courses is by W. L. Winston's "Operations Research, Application and Algorithms" and we use "WinQSB" software by Y-L Chang. Topics covered in IE 416 are: Linear programming, Simplex algorithm, LP sensitivity analysis, Goal programming, Transportation, Assignment, Transshipment, and Integer program. Topics covered in IE 417 are: Decision theory, Markov chain, and Queuing theory.

The OR courses have been gradually improved based on students' comments. These comments were part of a required portfolio containing a collection of the student's work during the quarter and his/her comments on how the work helped in the learning process and any suggestions for 
changes. Two previous papers contained information on these portfolios ${ }^{1,2}$, as well as incorporation of multimedia. These courses have a team project that utilizes the software, promotes team work skills, and leads to a professional report. Requirements for project report are on the class website. Reports are graded based on coverage of the OR technique, quality of written report, documentation, and professionalism. Correct grammar and spelling is a must for clear communication through the report.

Unfortunately, over the last several years, students' mathematical skills have been on the decline. As a result, I would spend the majority of class time explaining mathematical concepts, which meant there was insufficient time left for the development of critical thinking or discussion of various OR scenarios. Furthermore, the availability of powerful softwares that can solve OR problems in seconds facilitated the inadequate math skills, making it unnecessary for students to learn the necessary math.

In my experience, to optimize learning of OR concepts it is critical to spend a majority of the time improving students' problem formulation and analysis skills leading to a concise and professional report. In class, I highlight the fact that while softwares are powerful tools, they should be utilized in an intelligent manner. I stress that "garbage in is garbage out!" Moreover, I post a few of the students' solved assignments on the class website with my comments on them. This helps other students to better understand the level of work expected and the common mistakes they should avoid.

\section{2- LP Problem Formulation Tool}

To improve problem formulation skills in LP, I stress the formulation styles in Chapter 3 of our textbook by Dr. Winston. We have numerous discussions on the importance of defining proper decision variables. Discussions on defining decision variables ranges from how to consider minimum number of variables required for problem formulation (to simplify input into the software) to how to consider variables that assist in communicating problem formulation. (The $\underline{\text { Role of Summary Table and Decision Variables) }}$

I use one specific example to discuss the required preciseness in formulating the problem. This example indicates how the sign of a constraint can affect the optimal solution. (Appendix C, Versions of LP Formulation)

I have found that for most LP problems the given information can be summarized in a table format (matrix). Such summary tables assist students to easily and correctly formulate the problem. I show students how information in one row or one column of this summary table can be used to form a constraint. While I acknowledge that such problem summary tables are not applicable to all problems, I require students to create tables before formulating a problem. A sample problem summary table for the Oil Blending problem can be found in Appendix A. This tool proved to be very effective for students when developing the constraints of LP problems. 


\section{3- LP Report Writing}

Similarly, I encourage students to create a summary table of the important findings from the solution. This summary solution table will contain only the information from the software solution output that is of immediate importance in report writing. I stress the fact that these tables are valuable communication tools. Once more, I utilize the Oil Blending problem as an example to show students how they can obtain new information that was not obvious from the solution output. For instance, the software solution provides the amount of different oils used to produce each gas type. Because we have constraints for Octane requirements, we know that this solution has fulfilled these requirements. But the solution will not mention what is the exact Octane level for the optimal solution. I explain how the exact Octane level can be manually calculated and then be added to the summary solution table. This is an example of critical thinking. A sample solution summary table for this problem is in Appendix A.

We also have class discussions regarding the application of shadow price, reduced cost, and allowable ranges provided by the software. We talk about how and why some information from the solution output should be selected for a report and others should be disregarded. For example, we will not increase demand for Gas 1 since its shadow price is negative. Yet, in another case, if we plan to increase the availability of Oil 1 or Oil 2, Oil 1 should be selected since its shadow price is higher. I highlight the fact that though the software mathematically calculates the allowable ranges, these results may need to be refined for practical reasons when being mentioned in the report. For example, the software shows that unit profit per unit of Oil 1 used in Gas 1 is currently 21 and has an allowable range of $-\infty$ to 21 . From a practical point of view, profits cannot be negative. Therefore in a report the allowable range should be noted as 0 to 21 .

\section{4- Other OR Techniques}

A similar pedagogical approach is utilized for teaching other OR techniques. A list of links to specific example problems and guideline handouts is in Appendix C. In general, I require sensitivity analysis or experimentation to be performed for all OR techniques covered. Students should explain the motivation for performing specific sensitivity analysis. Sensitivity analysis should be performed within a practical or logical range. Students need to prepare a summary table or graph of the sensitivity analysis (or experimentation) that will be discussed in their Report to a Manager. This activity has enhanced students' understanding of the technique used.

Some examples of what is expected in Report to a Manager are listed below:

- When using Transshipment technique, it is required to analyze the final required capacity of warehouses. Based on the final capacity, student should make proper suggestions.

- When using Queuing theory, it is required to select an acceptable range for performance measures. The reasoning behind this selection needs to be explained. Later, these acceptable ranges are used to comment on how the system is performing and how it can be improved.

- When using Queuing theory, it is required to extend possible application of output results. For example, when dealing with a Machine Repair Model (M/M/R/GD/K/K), students must state how the output information can be used for scheduling of staff, determining space requirements in the repair shop, and eventually associating this with some monetary amount. 
- When using Decision tree, it is required to prepare a summary table of sensitivity analysis. This summary table should highlight a possible turning point in the decisions. The importance of decision turning point should be discussed from a practical perspective. A sample summary table is in Appendix B.

- When using Decision tree, there needs to be an adequate explanation of the expected value of return from practical point of view. For example, expected return is not the amount of return after one trial.

I prepared a table, called "Insights into the queuing theory" which compares three queuing models with respect to their input information, output information, and extended applications. This table assists students to gain deeper understanding of the queuing theory and appreciate possible applications of this technique.

\section{5- “Report to a Manager” as a Teaching Tool}

Throughout the years of teaching, especially Operations Research, I have noticed that students learn better when they must explain a solution in simple language. By emphasizing "Report to a Manager," I help students to better understand Operations Research techniques and their applications. Furthermore, the assignments emphasize the development of critical thinking and help to improve their communication skills through writing simple but concise reports.

The reports are written for a hypothetical manager who is not in the OR field. Therefore, the reports should not include technical language specific to OR or mathematical abbreviations. For example, students should not use the term "reduced cost" for a Linear Programming problem, rather they should explain its application. (Please refer to Appendix C for a list of links). Similarly, students should explain "expected profit/cost" in a practical manner when mentioning the result of a Decision Tree problem.

The reports should include findings from the sensitivity analysis as well as any other analysis from the solution output. I emphasize the use of effective communication tools, such as summary tables and graphs. For example, students can make a summary table of the sensitivity analysis for a Decision Tree which also indicates the turning point of decision-making. (Please refer to Appendix B). Moreover, I stress using a logical and practical range for the sensitivity analysis, as well as indicating the motivation for that specific sensitivity analysis.

I have prepared extensive handouts, which can be found on the course websites (Appendix C) to illustrate how to most effectively communicate the results in a report. I emphasize the importance of prioritizing information, such as in what order the information should be mentioned. For example, in an LP problem, first mention the optimal cost/profit, then explain the solution for decision-making purposes (that is basic/non-basic variables, reduced cost, binding/non-binding constraints, shadow price), and later discuss the result of several sensitivity analyses. Furthermore, I ask students to consider different types of managers who may require different types of information. I provided one LP example, the Oil Blending problem, to demonstrate all of these points, and more importantly the role of critical thinking in extracting more information from the solution. 
I spend a considerable amount of class time discussing how to write a report for different problems while trying to engage students in a discussion. Students are required to write reports for most of their homework assignments as well as for the project. Moreover, I included questions about these topics on quizzes and exams.

\section{6- Feedback from students}

In fall 2006, I asked students to provide feedback on the addition of "Report to a Manager" to the Operations Research I course. There were 37 students in this class. As part of their last homework assignment, each student sent an email providing his or her feedback in the form of an essay. Sample essays are in Appendix E. Later, after the final exam, each student filled out an anonymous questionnaire. The questionnaire and its tallied results are in Appendix D.

Below is the summary of some of the responses to the questionnaire based on Appendix D (IE 416):

\begin{tabular}{|c|c|c|}
\hline Question & Options & Students' Feedback \\
\hline $\begin{array}{l}\text { By how much have you improved } \\
\text { your skills as a result of writing } \\
\text { "Report to a Manager"? }\end{array}$ & $\begin{array}{l}\text { Not at all } \\
1-10 \% \text { improvement } \\
11-30 \% \text { improvement } \\
31-50 \% \text { improvement } \\
\text { More than } 51 \% \text { improvement }\end{array}$ & $\begin{array}{l}0 \% \\
8 \% \\
13.5 \% \\
19 \% \\
59.5 \%\end{array}$ \\
\hline $\begin{array}{l}\text { Did writing a "Report to a Manager" } \\
\text { help you in better understanding OR } \\
\text { concepts? }\end{array}$ & $\begin{array}{l}\text { Not at all } \\
\text { Somewhat } \\
\text { Considerable } \\
\text { Very much }\end{array}$ & $\begin{array}{l}6 \% \\
20.5 \% \\
29.5 \% \\
44 \%\end{array}$ \\
\hline $\begin{array}{l}\text { How much did the handouts on the } \\
\text { website (class notes and homework } \\
\text { solutions) help with respect to } \\
\text { learning about "Report to a } \\
\text { Manager"? }\end{array}$ & $\begin{array}{l}\text { Not at all } \\
\text { Somewhat } \\
\text { Considerable } \\
\text { Very much }\end{array}$ & $\begin{array}{l}5.5 \% \\
24 \% \\
40.5 \% \\
30 \%\end{array}$ \\
\hline $\begin{array}{l}\text { How much did discussions in class } \\
\text { help with respect to learning about } \\
\text { "Report to a Manager"? }\end{array}$ & $\begin{array}{l}\text { Not at all } \\
\text { Somewhat } \\
\text { Considerable } \\
\text { Very much }\end{array}$ & $\begin{array}{l}3 \% \\
24 \% \\
32.5 \% \\
40.5 \% \\
\end{array}$ \\
\hline $\begin{array}{l}\text { What do you think about the class } \\
\text { time allocated to "Report to a } \\
\text { Manager"? }\end{array}$ & $\begin{array}{l}\text { We spent too much time } \\
\text { We spent enough time as needed } \\
\text { We needed to spend more time }\end{array}$ & $\begin{array}{l}9 \% \\
70.5 \% \\
20.5 \%\end{array}$ \\
\hline
\end{tabular}

As the above table illustrates, a majority of students responded that they considerably improved their report writing skills and that the report helped them to better understand OR concepts. Furthermore, more than $70 \%$ of students responded that both the handouts on the web and the amount of time allocated to class discussions were helpful. This feedback confirms that report writing is an effective pedagogy for OR courses.

One interesting finding from students' feedback was with respect to the handout on the Oil Blending problem for LP. I prepared an extensive handout on problem formulation, sensitivity 
analysis, and report writing using this blending example from Winston's book. I used the example to demonstrate critical thinking and how different managers may be interested in different information. Students' feedback indicated that this example was too complicated for them. Therefore, it did not serve my purpose in their learning as expected.

Feedback from the students also indicated areas for future improvement. The following handouts will be added in future:

a) A checklist for report writing tailored to each OR technique

b) An example of a complete report

I used the same anonymous questionnaire for the Operations Research II course in winter 2007. The questionnaire and its tallied results are in Appendix F.

Below is a summary of some of the responses to the questionnaire found in Appendix F (IE 417):

\begin{tabular}{|c|c|c|c|}
\hline Question & Options & $\begin{array}{l}\text { Students' } \\
\text { Feedback } \\
\text { in IE } 417\end{array}$ & $\begin{array}{l}\text { Students' } \\
\text { Feedback } \\
\text { in IE } 416\end{array}$ \\
\hline $\begin{array}{l}\text { By how much have you } \\
\text { improved your skills as a } \\
\text { result of writing "Report to a } \\
\text { Manager"? }\end{array}$ & $\begin{array}{l}\text { Not at all } \\
1-10 \% \text { improvement } \\
11-30 \% \text { improvement } \\
31-50 \% \text { improvement } \\
\text { More than } 51 \% \text { improvement }\end{array}$ & $\begin{array}{l}8.3 \% \\
12.5 \% \\
16.7 \% \\
37.5 \% \\
25 \%\end{array}$ & $\begin{array}{l}0 \% \\
8 \% \\
13.5 \% \\
19 \% \\
59.5 \%\end{array}$ \\
\hline $\begin{array}{l}\text { Did writing a "Report to a } \\
\text { Manager" help you in better } \\
\text { understanding OR concepts? }\end{array}$ & $\begin{array}{l}\text { Not at all } \\
\text { Somewhat } \\
\text { Considerable } \\
\text { Very much }\end{array}$ & $\begin{array}{l}4.2 \% \\
33.3 \% \\
37.5 \% \\
25 \%\end{array}$ & $\begin{array}{l}6 \% \\
20.5 \% \\
29.5 \% \\
44 \%\end{array}$ \\
\hline $\begin{array}{l}\text { How much did the handouts } \\
\text { on the website (class notes } \\
\text { and homework solutions) help } \\
\text { with respect to learning about } \\
\text { "Report to a Manager"? }\end{array}$ & $\begin{array}{l}\text { Not at all } \\
\text { Somewhat } \\
\text { Considerable } \\
\text { Very much }\end{array}$ & $\begin{array}{l}16.7 \% \\
33.3 \% \\
29.2 \% \\
20.8 \%\end{array}$ & $\begin{array}{l}5.5 \% \\
24 \% \\
40.5 \% \\
30 \%\end{array}$ \\
\hline $\begin{array}{l}\text { How much did discussions in } \\
\text { class help with respect to } \\
\text { learning about "Report to a } \\
\text { Manager"? }\end{array}$ & $\begin{array}{l}\text { Not at all } \\
\text { Somewhat } \\
\text { Considerable } \\
\text { Very much }\end{array}$ & $\begin{array}{l}8.3 \% \\
50 \% \\
33.3 \% \\
8.3 \% \\
\end{array}$ & $\begin{array}{l}3 \% \\
24 \% \\
32.5 \% \\
40.5 \%\end{array}$ \\
\hline $\begin{array}{l}\text { What do you think about the } \\
\text { class time allocated to "Report } \\
\text { to a Manager"? }\end{array}$ & $\begin{array}{l}\text { We spent too much time } \\
\text { We spent enough time as needed } \\
\text { We needed to spend more time }\end{array}$ & $\begin{array}{l}8.3 \% \\
58.3 \% \\
33.3 \%\end{array}$ & $\begin{array}{l}9 \% \\
70.5 \% \\
20.5 \%\end{array}$ \\
\hline
\end{tabular}

As compared to IE 416, in IE 417 I do not have as many handouts on, nor do I spend as much time stressing the importance of, report writing. One reason for this is that the techniques covered in IE 417 are more difficult for students and therefore I spend more time explaining these concepts. Another reason is that most students (not all) have taken IE 416 before and I hope they continue improving their skills on report writing on their own rather than relying on me to stress its importance. It is apparent from the responses that improvements in report writing as well as understanding of OR techniques has gone down in IE 417 as compared to IE 416 
(from about $75 \%$ to about $62 \%$ ). Also, $33.3 \%$ of IE 417 students indicated that they needed more time on report writing compared to $20.5 \%$ from IE 416 . This again indicates the pedagogy impact of the writing report approach to these courses. I will provide more handouts and stress more on this aspect in IE 417 in the future.

\section{7- Conclusion}

There are many extraneous obstacles in teaching OR courses. These include both the time limitation on covering various important topics as well as the inadequate mathematics background of many students. It is important to efficiently use the resources available to teach OR concepts and improve analytical and communication skills. This is best achieved through report writing. "Report to a Manager" is used as a tool to enhance learning important OR concepts as well as encouraging students to critically think about the solution outputs from OR softwares. This implemented pedagogy has proved to be effective.

\section{Bibliography}

[1] Parisay, S., "Multimedia and Assessment Techniques in an Operations Research Course", Session 2257, 2000 ASEE Annual Conference Proceedings.

[2] Parisay, S., "Implementation of Classroom Assessment Techniques and Web Technology in an Operations Research Course", Session 2663, 1999 ASEE Annual Conference Proceedings. 


\section{Appendices:}

\section{Appendix A: Sample of Summary Tables to Assist Formulation and Report Writing for LP}

Linear Programming: Blending Example from Winston

- For details on the problem statement please refer to:

http://www.csupomona.edu/ spparisay/Courses/SharedExamples/LP-blending/SuncoBlendingproblem.doc

Summary of problem (an efficient tool to assist formulation):

\begin{tabular}{|c|c|c|c|c|c|c|c|c|}
\hline Sulfur & Octane & Sales & Meet demand & GAS & Decis & varia & & \\
\hline $\begin{array}{l}\text { At most } \\
1 \%\end{array}$ & $\begin{array}{l}\text { At least } \\
10\end{array}$ & $\$ 70$ & 3000 & 1 & $\mathrm{X} 11$ & $\mathrm{X} 21$ & X31 & A1 \\
\hline $\begin{array}{l}\text { At most } \\
2 \%\end{array}$ & At least 8 & 60 & 2000 & 2 & $\mathrm{X} 12$ & $\mathrm{X} 22$ & $\mathrm{X} 32$ & $\mathrm{~A} 2$ \\
\hline $\begin{array}{l}\text { At most } \\
1 \%\end{array}$ & At least 6 & 50 & 1000 & 3 & $\mathrm{X} 13$ & $\mathrm{X} 23$ & $\mathrm{X} 33$ & A3 \\
\hline \multicolumn{5}{|c|}{ OIL } & 1 & 2 & 3 & \\
\hline \multicolumn{5}{|c|}{ Purchase price $\$ /$ barrel } & $\$ 45$ & 35 & 25 & \\
\hline \multicolumn{5}{|c|}{ Available oil, max barrel/day } & 5000 & 5000 & 5000 & \\
\hline & \multicolumn{4}{|c|}{ Octane rating } & 12 & 6 & 8 & \\
\hline & \multicolumn{4}{|c|}{ Sulfur content } & $0.5 \%$ & $2.0 \%$ & $3.0 \%$ & \\
\hline
\end{tabular}

- For details on the solution and Report to the Manager please refer to:

http://www.csupomona.edu/ sparisay/Courses/SharedExamples/LP-blending/SuncoBlendingreport.doc

Summary of the above solution (a tool to assist report writing):

\begin{tabular}{|c|c|c|c|c|c|c|c|c|}
\hline Sulfur & Octane & Total sales & Production & GAS & Optimal & alue of de & sion va & ables \\
\hline $\begin{array}{l}1 \%(\max \\
1 \%)\end{array}$ & $\begin{array}{l}10 \\
(\min 10)\end{array}$ & 210000 & 3000 & 1 & $\begin{array}{l}X 11= \\
2000\end{array}$ & $\begin{array}{l}\mathrm{X} 21= \\
1000\end{array}$ & $\begin{array}{l}\text { X31 } \\
=0\end{array}$ & $\begin{array}{l}\text { A1 } \\
=0\end{array}$ \\
\hline $\begin{array}{l}2 \%(\max \\
2 \%)\end{array}$ & $\begin{array}{l}8.08(\mathrm{~min} \\
10)\end{array}$ & 570000 & 9500 & 2 & $\begin{array}{l}X 12= \\
2200\end{array}$ & $\begin{array}{l}X 22= \\
4000\end{array}$ & $\begin{array}{l}\text { X32 } \\
= \\
3300\end{array}$ & $\begin{array}{l}\text { A2 } \\
= \\
\mathbf{7 5 0}\end{array}$ \\
\hline $\begin{array}{l}1 \%(\max \\
1 \%)\end{array}$ & $\begin{array}{l}11.2(\min \\
10) *\end{array}$ & 50000 & 1000 & 3 & $\begin{array}{l}X 13= \\
800\end{array}$ & $\mathrm{X} 23=0$ & $\begin{array}{l}\text { X33 } \\
=200\end{array}$ & $\begin{array}{l}\text { A3 } \\
=0\end{array}$ \\
\hline \multicolumn{5}{|c|}{ OIL } & 1 & 2 & 3 & \\
\hline \multicolumn{5}{|c|}{ Total purchase $\mathbf{\$ 4 8 7 , 5 0 0}$} & 225000 & 175000 & 87500 & \\
\hline \multicolumn{5}{|c|}{ Required oil, barrel/day } & 5000 & 5000 & 3500 & \\
\hline
\end{tabular}




\section{Appendix B: Sample of Summary Table for Sensitivity Analysis for Decision Tree}

Decision Tree: Colaco Soda Example from Winston

- For details on the solution and Report to a Manager please refer to:

http://www.csupomona.edu/ sparisay/Courses/SharedExamples/DecisionTree/ColacoDecisionTr ee-report.doc

Summary table for sensitivity analysis on probability:

\begin{tabular}{|l|l|l|l|}
\hline Probability & $\begin{array}{l}\text { Expected } \\
\text { Outcome }\end{array}$ & $\begin{array}{l}\text { WinQSB } \\
\text { Output } \\
270000\end{array}$ & $\begin{array}{l}\text { MarketYN1 -> } \\
\text { nationalSF1 } \\
\text { Make }\end{array}$ \\
\hline 0.5 & 270000 & $\begin{array}{l}\text { MarketYN1 -> } \\
\text { nationalSF1 }\end{array}$ & No test market, then market nationally \\
\hline 0.6 & 288000 & localSF & $\begin{array}{l}\text { Test market, if success then market } \\
\text { nationally, if failure then do not market } \\
\text { nationally }\end{array}$ \\
\hline 0.7 & 312000 & localSF & $\begin{array}{l}\text { Test market, if success then market } \\
\text { nationally, if failure then do not market } \\
\text { nationally }\end{array}$ \\
\hline 0.8 & & &
\end{tabular}

Turning point is between 0.6 and 0.7 probability.

\section{Appendix C: List of Links to Example Problems and Handouts in Course web sites}

Linear Programming: Blending Example from Winston

- LP file of WinQSB: http://www.csupomona.edu/ sparisay/Courses/SharedExamples/LPblending/SUNBLEND.LPP

- Problem statement and summary:

http://www.csupomona.edu/ sparisay/Courses/SharedExamples/LP-blending/SuncoBlendingproblem.doc

- WinQSB solution: http://www.csupomona.edu/ sparisay/Courses/SharedExamples/LPblending/SuncoBlending-solution.doc

- WinQSB sensitivity analysis:

http://www.csupomona.edu/ sparisay/Courses/SharedExamples/LP-blending/SuncoBlendingsensitivityFor416.doc

- Report to the manager: http://www.csupomona.edu/ sparisay/Courses/SharedExamples/LPblending/SuncoBlending-report.doc 
Linear Programming: Toy Example, version 2

- Linear programming problem, more sensitivity analysis and report writing discussions http://www.csupomona.edu/ sparisay/Courses/SharedExamples/LP-toys/Toy-LPproblemSolution-V2.doc

Linear Programming: The Role of Summary Table and Decision Variables

- http://www.csupomona.edu/ sparisay/Courses/SharedExamples/HW-LP/P97-4.doc

Liner Programming: Versions of LP Formulation

- http://www.csupomona.edu/ sparisay/Courses/SharedExamples/HW-LP/P92-

11 formulationVersions.doc

Transshipment Problem:

- Writing Report for Transshipment:

http://www.csupomona.edu/ sparisay/Courses/SharedExamples/transportation/transshipmentreport.doc

Decision Tree:

- Report writing guidelines

http://www.csupomona.edu/ sparisay/Courses/ie417/handout/Report-writing-DecisionTree.doc

Decision Tree: Colaco Example: 3 on page 758 of Winston:

- DAA file of WinQSB:

http://www.csupomona.edu/ sparisay/Courses/SharedExamples/DecisionTree/COLACO.DAA

- Problem and its WinQSB solution:

http://www.csupomona.edu/ sparisay/Courses/SharedExamples/DecisionTree/ColacoDecisionTr ee-problemSolution.doc

- Sensitivity analysis using WinQSB:

http://www.csupomona.edu/ sparisay/Courses/SharedExamples/DecisionTree/ColacoDecisionTr ee-sensitivity.doc

- Report to manager:

http://www.csupomona.edu/ sparisay/Courses/SharedExamples/DecisionTree/ColacoDecisionTr ee-report.doc

Queuing Theory:

- Report writing guidelines:

http://www.csupomona.edu/ sparisay/Courses/ie417/handout/Report-writing-Queue.doc

- Insights into the Queuing Theory

http://www.csupomona.edu/ sparisay/Courses/SharedExamples/Queue/queueInsight.htm

Course web sites:

- Operations Reseach I: http://www.csupomona.edu/ sparisay/Courses/ie416

- Operations Reseach II: http://www.csupomona.edu/ sparisay/Courses/ie417 


\section{Appendix D: Anonymous questionnaire on the effect of "Report to a Manager"}

This questionnaire was distributed after final exam to all 37 students in IE 416 (Operations Research I), fall 2006.

IE 416 Feedback on "Report to a Manager" emphasis of IE 416 Fall 2006

Please give feedback on just one aspect of this course, IE 416, in terms of learning what information should be included in a "Report to a Manager" and how. My goal was to prepare you for the "Report to a Manager" by developing skills on how to analyze software output, how to try to extract more information, and how to communicate these results to different levels of managers. As tools to help with this goal I put several handouts on the website (i.e. Blending problem and homework solutions), we had discussions in class, and there were quizzes and questions on the midterm.

1- How much have you improved in writing a report to a manager as a result of this course, IE 416? Circle one below.

Not at all

$1-10 \%$ improvement

$11-30 \%$ improvement

$31-50 \%$ improvement

More than $51 \%$ improvement
0 responds

3 responds

5 responds

7 responds

22 responds

2- By how much were handouts on the website (class notes and homework solutions) helpful in respect to learning about "Report to a Manager"? Circle one below.

$\begin{array}{ll}\text { Not at all } & 2 \text { responds } \\ \text { somehow } & 9 \text { responds } \\ \text { considerable } & 15 \text { responds } \\ \text { very much } & 11 \text { responds }\end{array}$

3- Was there any specific handout that helped you most? Please name it and explain why and how it was helpful.

4- Do you suggest any more handouts on "Report to a Manager"? What areas and how?

5- By how much were discussions in class helpful in respect to learning about "Report to a Manager"? Circle one below.

$\begin{array}{ll}\text { Not at all } & 1 \text { responds } \\ \text { somehow } & 9 \text { responds } \\ \text { considerable } & 12 \text { responds } \\ \text { very much } & 15 \text { responds }\end{array}$


6- Was there any specific discussion that helped you most? Please explain why and how it was helpful.

7- What do you think about our class time allocation on writing a "Report to a Manager"? Circle one below.

We spent too much time not needed 3 responds

We spent enough time as needed 24 responds

We needed to spend more time 7 responds

8- Do you suggest more discussions in class on "Report to a Manager"? What areas do need more discussions?

9- Did writing a "Report to a Manager" help you in better understanding OR concepts? Circle one below.

$\begin{array}{ll}\text { Not at all } & 2 \text { responds } \\ \text { somehow } & 7 \text { responds } \\ \text { considerable } & 10 \text { responds } \\ \text { very much } & 15 \text { responds }\end{array}$

10- In what other ways can this course be designed to help with this goal (Report to a Manager)? Please provide specific examples.

Several students asked for a "check list" for items required in Report to a Manager as well as a sample of a complete report. 


\section{Appendix E: Sample of essay homework on the effect of "Report to a Manager"}

Each student was supposed to send an email providing their feedback as an essay for homework in the last week of IE 416 (Operations Research I), fall 2006. Below are several sample emails.

\section{1- Homework statement:}

Comment on your writing skills in the OR field as obtained from the "Report to a Manager". My goal was to prepare you for the "Report to a Manager" by developing skills on how to analyze software output, how to try to extract more information, and how to communicate these results to different levels of managers.

As tools to help with this goal I put several handouts on the website (i.e. Blending problem and homework solutions), we had discussions in class, and there were quizzes and questions on the midterm.

Please specify how any of these tools helped you in writing the final report. In what other ways can this course be designed to help with this goal? Please provide specific examples of the effect these tools had in your learning process in the OR course.

\section{2- Students' essays:}

By: Ms. Vijetha Bathala

My writing skills improved when writing to a manager. I learned the order of importance and different aspects of the solution. When writing a report to a manager I learned the wording choices like simple English instead of operations research language. I also learned that not to present the whole solution which can be confusing to the manager instead point out the main facts and give one or two examples. By making the solution in a table also shows the solution in an organized manner and it is also easy to look at and can get a final conclusion. The lecture on the Sunco oil also helped how to write. The quizzes also covered different situations of the problem solution to think and write slightly different on the solution.

We used the example writing a report on Sunco Blending Problem in the final report. We also used the sheet with different type of managers list (financial manager, quality manager, etc) to make sure that we covered the report for all the managers. As for the reduced cost and shadow price we understood the concept and analyzed our solution and wrote a report. The video lecture also helped us to understand the concept more detailed and slowly. The posted solutions on the website helped in writing the report. When we saw the corrected solutions and reports on the website we realized what is missing in the report and what should be added. Some other changes would be to provide some sheets (2-3) with official manager reports, real if possible, on different aspects not only on oil but also on different manufactured products, software, etc. This would help to analyze and look at how different types of solutions and reports can be obtained and how the companies would use the data in the solution in real life too.

More comments are available on the web site. 


\section{Appendix F: Anonymous questionnaire on the effect of "Report to a Manager"}

This questionnaire was distributed to 24 students in IE 417 (Operations Research II), winter 2007.

IE 417 Feedback on "Report to a Manager" emphasis of IE 417 Winter 2007

This feedback sheet concentrates on just one of the aspects of this course, IE 417. The selected aspect is what you learned with regards to what types of information should be included in a "Report to a Manager" and how it should be presented. My goal was to prepare you for the "Report to a Manager" by developing skills on how to analyze software output, extract more information, and communicate these results to a manager. To help with this goal I had several handouts on the website (i.e. Report writing guidelines for Decision Tree and Queuing Theory, Report to a manager for DT example, discussion of application of Semantic Network to develop applications for queuing theory, and homework solutions), we had discussions in class, and there were quizzes and questions on the midterm. Finally, you finished your project which includes a report.

1- How much have you improved in writing a report to a manager as a result of this course, IE 417? Circle one below.
Not at all
2 responds
$1-10 \%$ improvement
3 responds
$11-30 \%$ improvement
4 responds
$31-50 \%$ improvement
9 responds
More than $51 \%$ improvement
6 responds

2- How much did handouts on the website (class notes and homework solutions) help in respect to learning about "Report to a Manager"? Circle one below.

$\begin{array}{ll}\text { Not at all } & 4 \text { responds } \\ \text { somehow } & 8 \text { responds } \\ \text { considerable } & 7 \text { responds } \\ \text { very much } & 5 \text { responds }\end{array}$

3- Was there any specific handout that helped you most? Please name it and explain why and how it was helpful.

4- Do you suggest any more handouts on "Report to a Manager"? What areas and how?

5- How much were discussions in class helpful in respect to learning about "Report to a Manager"? Circle one below.

Not at all 2 responds 


$\begin{array}{ll}\text { somehow } & 12 \text { responds } \\ \text { considerable } & 8 \text { responds } \\ \text { very much } & 2 \text { responds }\end{array}$

6- Was there any specific discussion that helped you most? Please explain why and how it was helpful.

7- What do you think about the amount of time allocated to writing a "Report to a Manager"? Circle one below.

We spent too much time not needed 2 responds

We spent enough time as needed 14 responds

We needed to spend more time 8 responds

8- Do you suggest more discussions in class on "Report to a Manager"? What areas do need more discussions?

9- Did writing a "Report to a Manager" help you to better understand OR concepts? Circle one below.

$\begin{array}{ll}\text { Not at all } & 1 \text { responds } \\ \text { somehow } & 8 \text { responds } \\ \text { considerable } & 9 \text { responds } \\ \text { very much } & 6 \text { responds }\end{array}$

10- In what other ways can this course be designed to help with this goal (Report to a Manager)? Please provide specific examples.

Several students mentioned that as they had IE 416 in previous quarter, this aspect of the course did not contribute as much to their report writing skill. Several students asked for more examples 